\title{
Behind the scenes of the Estonian TV series The Bank: Ideas, practices, and stories. An interview with its creators.
}

$\$$ sciendo

ALESSANDRO NANì, Tallinn University, Estonia; email: nani@tlu.ee ULRIKE ROHN, Tallinn University, Estonia; email: ulrike.rohn@tlu.ee ANDRES KÕNNO, Tallinn University, Estonia; email: akonno@tlu.ee 
The Bank (Pank) is a ten-episode Estonian TV drama series originally broadcast during prime time in autumn 2018 on ETV, the main channel of Estonian Public Service Broadcasting (ERR).

Set in the post-Soviet 1990s in

Estonia, also known as the transition period of Estonian society, The Bank is based on a true story, focusing on the birth, growth and acquisition of Hansapank (Nord Bank in the TV series), which was to become the most successful bank in Estonia. The story mainly focuses on the birth, growth and Swedish acquisition of Hansapank (which would become the most successful bank in Estonia) and of the lives of its management team.

The series is special in the Estonian context for several reasons. Firstly, it was included in the Estonian 100 film program that commemorated the $100^{\text {th }}$ anniversary of the Estonian republic in 2018. As such, the series received special funds (the highest amount ever received by a TV series), in fact, the Estonian 100 funded forty short documentaries, one animation, six feature films, two documentaries and one TV drama series - The Bank.

Secondly, the series has already been sold to several countries, including Finland, Lithuania, Hungary and the US. More countries are likely to follow.

The series was financed in large part by special state funding through the Estonian Film Institute (EFI), as part of the commemoration of the one hundredth anniversary of the Republic of Estonia (Eesti Vabariik 100, shortened in English to the Estonia 100). This financial support, which was considerably larger than the usual funds available each year to the film industry, consisted of a lump sum that was granted to just one TV production, with the condition that the winner should "represent" Estonia both nationally and internationally. It should tell a story relevant to the whole nation and be potentially attractive to foreign audiences.

This element is fundamental to the reading of both the production and the reception of the series because it framed the obligations that the producers had to fulfil and the possible expectations of the Estonian audience towards the series.

The series chosen to commemorate Estonia's anniversary, which was introduced to the audience as a fictional drama and an artistic re-visitation of real events, depicts a period still vivid in Estonians' minds. This created a buzz, expectations and potentially opposition.

The authors of this paper, Alessandro Nanì, Ulrike Rohn and Andres Kõnno, interviewed the creators of the series in the summer of 2019. The aim of these interviews was to better understand the ideas, practices and stories behind the production of the series. During the process, Nani focused on the understanding that the creators of The Bank's had of their audiences, Rohn was mainly interested in the influence that a potential ambition to sell the series internationally had on the production of the programme, and Kõnno focused on memory and, in particular, the narration of a contested period that was yet to be told as a work of art.

The researchers interviewed two screenwriters and one producer of the TV series. These were: Eero Epner, a professional playwright for whom this was his first experience as a screenwriter; Tarmo Jüristo, a former trader at Hansapank who had become a playwright and for whom this was also his first experience as a screenwriter; and Paul Aguraiuja, a theatre producer for whom this was his first experience producing a television series.

The following presents a summary of these interviews that followed the same or similar questions.

\section{Why did you decide to write/ produce Pank in the first place? What moved you?}

Tarmo Jüristo: There is actually a bit of a longer backstory to this. So, for one thing, I was one of the early employees of Hansapank - so, I had this personal background. At some point, Hansapank had this almost mythical place in the folklore of the early 
'90s, as this was the original success story. Before Skype and before everything else, this was the first one [business], where people got really rich. I mean, there were others, like in the transit sector and so on, but this [banking] was a very visible part of Estonian early capitalism.

Perhaps this was the reason why, at some point, we were looking into putting that story on the stage in a theatre. Then, several years later, we were already involved with theatre, driving to Narva with Eero Epner, the other writer, and he mentioned that he had seen somewhere the call for projects for the Estonia 100 year anniversary, including the call for an original TV series. He just threw out the idea: "remember, we had this idea of doing this Hansapank thing for the theatre - why don't we do it as a TV series?"

We weren't seriously thinking of actually doing it. My first objection was: "well, we tried for the theatre; we couldn't find an angle; why would it be different for a TV series?" Why would it work there if it didn't work in theatre? We were trying to think of the way it could be made to work. At one point I suggested: "let's make it a strory about a person rather than about the institution." [Through this] it would be a story of a country in a transition, with several things happening; and that was the angle through which we tied it to the Estonia 100 project.

Eero Epner: I guess there were many triggers. For example, one of the triggers was that for both me and Tarmo, it was the first time writing a TV series, and it seemed like a nice challenge. But I guess the main trigger was that we felt that there is something in this story, in this real-life story of Hansapank. And when I tried to put my finger on it, what was this something [special] in this story? I would say that there was some kind of energy [at the time of the Estonian Restoration of Independence], which we felt or which at least I felt - that is lacking from today's society. This energy was a kind of combination of total anarchy and, on the other hand, it was very structured period that had a certain goal, because people wanted to achieve something. It wasn't just [a time of] chaos, but [a period when] people's goals were changing all the time. This combination of anarchy and people having [concrete] desires was very, how to say, fanciful. This was, for me, the main trigger [about this story].

Paul Aguraiuja: Before moving on to the Pank [project], I was the CEO of theatre N099 and had not been involved in any film business or TV production business for more than 7 or 8 years. I did work in film production before that, but Pank grew out of N099, because the team that started it Eero and Tarmo - had been writing for N099 and I had produced these plays. So for us it was a natural way to continue with the collaboration that grew out from N099.

\section{But why this story in particular?}

Paul Aguraiuja: Because for me it is about the most important era in the development of this country.

\section{What is your under-standing of the '90s? How do you feel about the importance of this period?}

Paul Aguraiuja: I believe that the foundation to everything that is going on now -was laid back then. Yet, nobody had told this story before. Also, for me it's really important to try to sell stories or tell stories that are internationally transportable. The story of the Estonian 1990s is something that the world has not heard about. So that's why for me this was the most important and interesting topic to start producing a series about.

When producing the series, my goal was to avoid showing the 90 s as a hero (sic). I believe that when we talk about the influence of the " 90 s then we as authors cannot take the position of showing that this period was good for everyone. I don't want to be the one who influences the understanding of an era. I want people to start thinking about the era, but I don't want to tell them that this is the truth. 


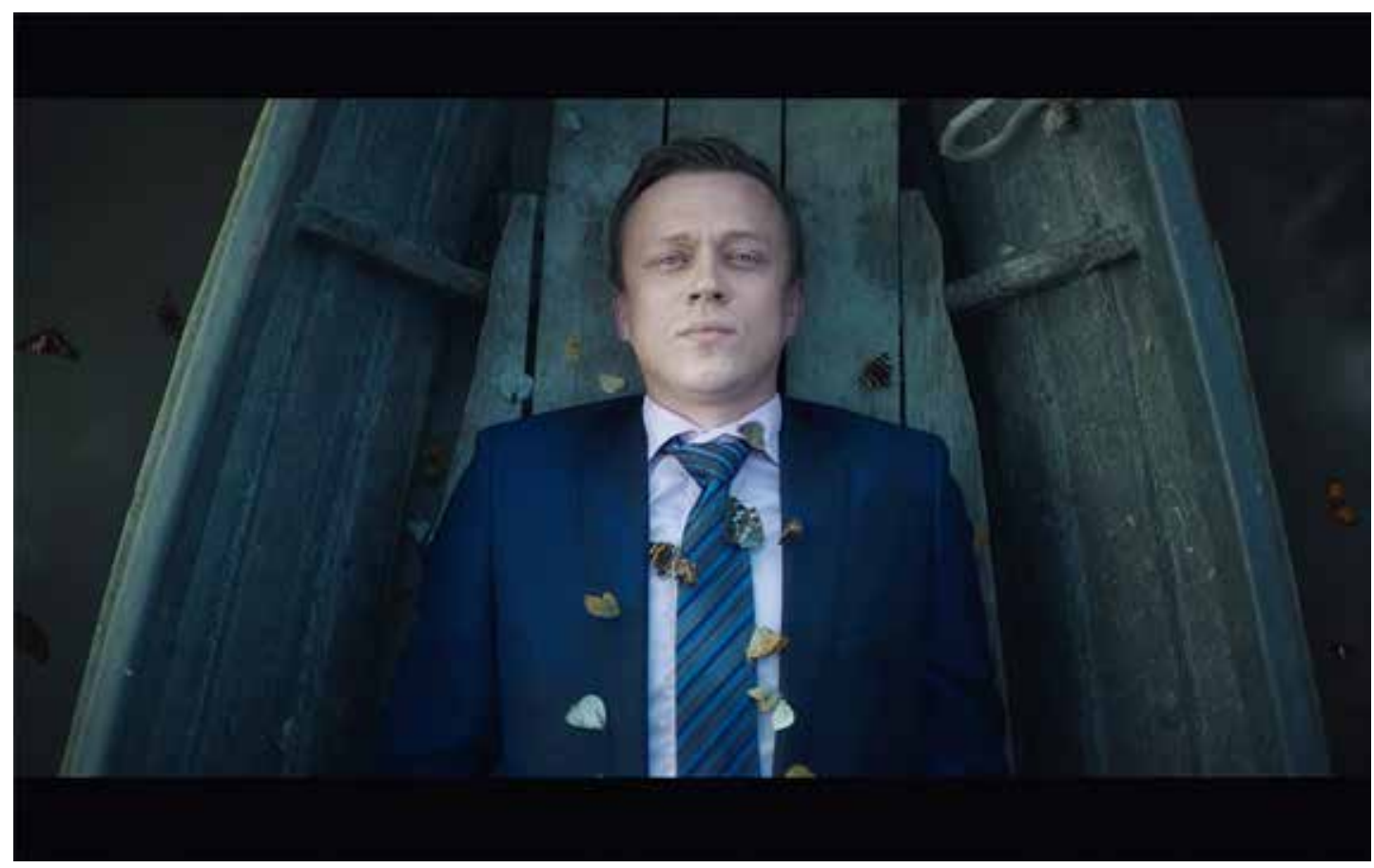

FIGURE 1. Toomas Pisuke (Sergo Vares). (Photo: Jekaterina Abramova). 
I was born in 1980, so for me the memories from the " 90 s are about my childhood. These memories are heavily influenced by the stories of others that I have heard - from my parents, from my parents' friends, from my older friends, and from my later colleagues. But I have still gained the understanding that the 90s were really unique in the sense that quite rarely in history does a country gets a chance to start from scratch. If you think about the 90 s in Estonia, then everybody who used to be somebody before was suddenly "deleted“. All the social capital that they had built up was instantly gone. Completely new people had to take over all positions. Of course, some of the old-school people from the old time remained, but most of the people in politics, in economics were new. Basically, it means that all business relationships started from scratch. All hierarchies in the society had to be restarted from the beginning. This has played such an influential role on how we are operating today. There are so many people that have not been affected by the success of Estonia and who have not gained anything from it. That's what we are trying to show in Pank, that because of those hardcore capitalist decisions, some people became really poor and some people became really rich, and now after all those years, whatever the government has been doing, they can't turn it around anymore. They can't make it more equal, because of those decisions that were made in the " 90 s.

[...] For me, [the period, the '90s] it's not nasty and it's not idealized in a positive way. It's just something that had to be done. It's just a story of growing up, similar to teenage years. You have to make your own stupid mistakes to become normal.

Tarmo Jüristo: If you look at what Estonia is right now, then the events of early ' 90 s, in my opinion, have had a very big effect on the present. Because this is the time when the society, the relations between people and values were built. Everything could have gone the other way. It wasn't predetermined in any sense, because if you look at, for instance, Latvia - we started pretty much in a similar situation, but we ended up in quite different places. This is the reason behind telling this story. It's trying to deal with this part of the history. There are also quite few movies about the " 90 s coming out. There seems to be enough of a historical distance from these times [in order to aesthetically analyse them]. You can actually look back at the time and distance yourself to an extent from the events. There's a whole generation who has grown up and who only knows about these times through second-hand stories. I was talking at an event on the Holocaust day a few years ago [2017] and I realised that being born in 1971 means that I was born exactly 26 years after the Second World War. When I grew up, then of course I had heard stories about the war, how my parents were kids at that time and how my grandparents were fighting. At the time you could go to the forest and find Wehrmacht helmets and old guns and all sort of thing like this. There were those physical artifacts of that time still around. But for me, this was incomprehensible. It was not something I could really relate to. There were movies and there were stories and I was told about the history in school, but it did not relate to my lived experience. Now, looking back at 2017, the year I gave the interview, I realised that since Estonia regained its independence in 1991, from 1991 to 2017 there were 26 years.

Eero Epner: This seemed one of the most interesting starting points for writing a TV series, because, on the one hand, this very unique energy of the " 90 s was very interesting. But, on the other hand, we wanted to also bring in the so-called 'normal people'. We wanted to show the marginalised people as well and how the big decisions affect their life. The contradiction of the ' 90 s was also interesting. We did not want to idealise this period, but also show some side-effects of the era as well. Eventually, it all comes down to personal experiences. I have heard, for istance, that young people who don't have this personal experience of 
the ' 90 s, have quite a struggle with the TV series. They don't believe it to be accurate and they simply do not understand it.

\section{Pank has the stamp of your personal experience on it, but the ' 90 s is quite rich in all sorts of events - both inside banking and politics. Did you consider including some of the other prominent story- lines as well, either from politics or other banks?}

Tarmo Jüristo: Yes, we did, but in the end, we had to keep it focused. Initially, we decided to bring in the Hoiupank's storyline and expand the narrative this way. We could have, of course, brought in lots of other things, but we were trying to hold a central focus so that it wouldn't be all over the place.

Eero Epner: This is one of the decisions I'm still ready to defend. There were many mistakes, but this was our conscious aim, not to put the story of Hansapank into the political context, and also not the overall economical context, but rather into the context of people. We wanted to look at the phenomenon of Hansapank through people and to make it a very personal story. The losses and wins that are there, aren't the losses and wins for Estonian politics and the Estonian economy, but rather, they are the wins and losses of those people, who were either working in Hansapank or who were the marginalised people living in the countryside.

The chronological coherence and what else was happening in Estonian economy this is something we cut out, because we wanted to tell another story. A story about how the social transition affected people's lives and dreams. It is a little bit sentimental to show all the time on the screen people who cry and laugh, there are also other possibilities, but this was a conscious choice. I guess we chose this direction after we interviewed the people who were the founders of Hansapank. We saw how personal it was for them, not only the founding of
Hansapank, but also, how personally they took it when Swedbank took over Hansapank and they lost it. The loss was very personal for them. The sidestory of Kodupank and the attempt to protect it from the merger with Hansapank was also very personal for those involved. I would say that for all to whom we spoke, it was the most important thing in their lives, and they partially define themselves, even now, through what they did in the " 90 s. I guess the idea that we should choose this human perspective in order to show that this story started from the interviews.

\section{Do you think the reception has something to do with having lived through that period versus not having lived through that period? That the idealisation and under- standing of the period is different?}

Paul Aguraiuja: All the people who were active in the " 90 s are still alive, they are still active in society. Thus, it is really hard to analyse history that is so close to the present. As it now, it is $20-25$ years from the founding of Hansapank; we can start talking about the '90s as history. Let's say, 10 years ago, when you talked about the '90s, it was still contemporary.

Most of the team, who did Pank were kids in the '90s so we don't have such deep personal regrets regarding it. But our parents and grandparents have personally experienced something bad that happened in the ' 90 s. The memories are very different. I think we were able to play with the elements of history much more freely, because it didn't mean anything personal to us. So, in that sense, I agree with you that it might be the cause for the different reception.

Eero Epner: The story of how the '90s looked in Eastern Europe is a perspective that hasn't been told yet. At least, we had the feeling that this is something new for a Western viewer. So, if they look at it - what they should receive is, I hope, a different perspective. Hopefully, they will see this strange energy of the period. As much as I 
have understood from Paul, who has shown this TV series to many foreign audiences, they don't believe that this was really happening. Although this is not a documentary, the series offers a new perspective on what was happening in the world in the ' 90 s.

\section{Do you know what exactly it is that the foreign audiences had difficulties accepting as historically accurate?}

\section{Eero Epner: Several things. For instance,} that changes can happen so fast as they did back then; that social relations were not so structured and hierarchical as they usually are; that all the meanings and hierarchies are being changed all the time; that nothing is stable and that very young people can also lead a bank or lead the State or whatever. This attitude that everything can change in a week or in a month, and that the changes are highly significant. This is an experience, I believe, that Western Europe hasn't experienced for a very long time. Perhaps this is the new perspective.
Remarks by the interviewers: Regard- ing the translatability of the Estonian ' 90 s, the scriptwriters Tarmo Jüristo and Eero Epner were a bit more scepti- cal about telling the story in a specific manner that would make it fit for foreign audiences. As we look at the answers of the creators of „Pank“, it seems that the understanding of the translatability of the Estonian sense of nostalgia for the '90s into what the hypothetical international audience thinks about the '90s somewhat overlaps. But there are also small differences.

What Paul Aguraiuja calls the internationally transportable story of the Estonian '90s has two rather different interpretations from Tarmo Jüristo and Eero Epner. What all the authors equally emphasized was the understanding that the aim was not to create a documentary or - a documentary-like interpretation of the ' 90 s. Instead, the team decided to focus on the storytelling with- out paying too much attention towards the documentalistic value of the series. So to speak: art for art's sake.

\section{Did you do anything specific in order to sell it abroad instead of making it especially for the Estonian audience?}

Tarmo Jüristo: Nothing too specific. It was something that you had in mind and in some cases, we were thinking that, "okay, if we do this part, then how would it come across, let's say, in Sweden or in Finland?". But we weren't changing anything for the international audiences. Perhaps one of the things that we did - and there were different reasons for this - was Kati Outinen playing one of the important side parts. When we tried to convince her to come and join, then the international audience was also something that registered definitely in our minds. We were talking about this with Eero and, at some point, I also believe we talked with Paul - that having Kati Outinen could be something that would be helpful for the Finnish market. That there is an internationally recognized Finnish actor in the series.

Eero Epner: It was important for us that it would be understandable not only in Estonia, but also in foreign countries. That meant that we wanted to generalise, not to be too specific, so that a person who doesn't know the whole context of '90s Estonia will understand also what is going on. But I would say that other concerns were a little bit more important. For example, we almost totally cut the political context. There were several reasons. There are some politicians in the TV series, but they are in very marginal positions. One of the reasons we cut the political context was because then we'd have to deal with it; we'd have to also explain the political setting. And it's just too much for one TV series to do, explain both the overall atmosphere, the political context, the business context, and so on. But the other reason for cutting politicians out was also the fact that, so far, the ' 90 s, especially the beginning of ' 90 s 


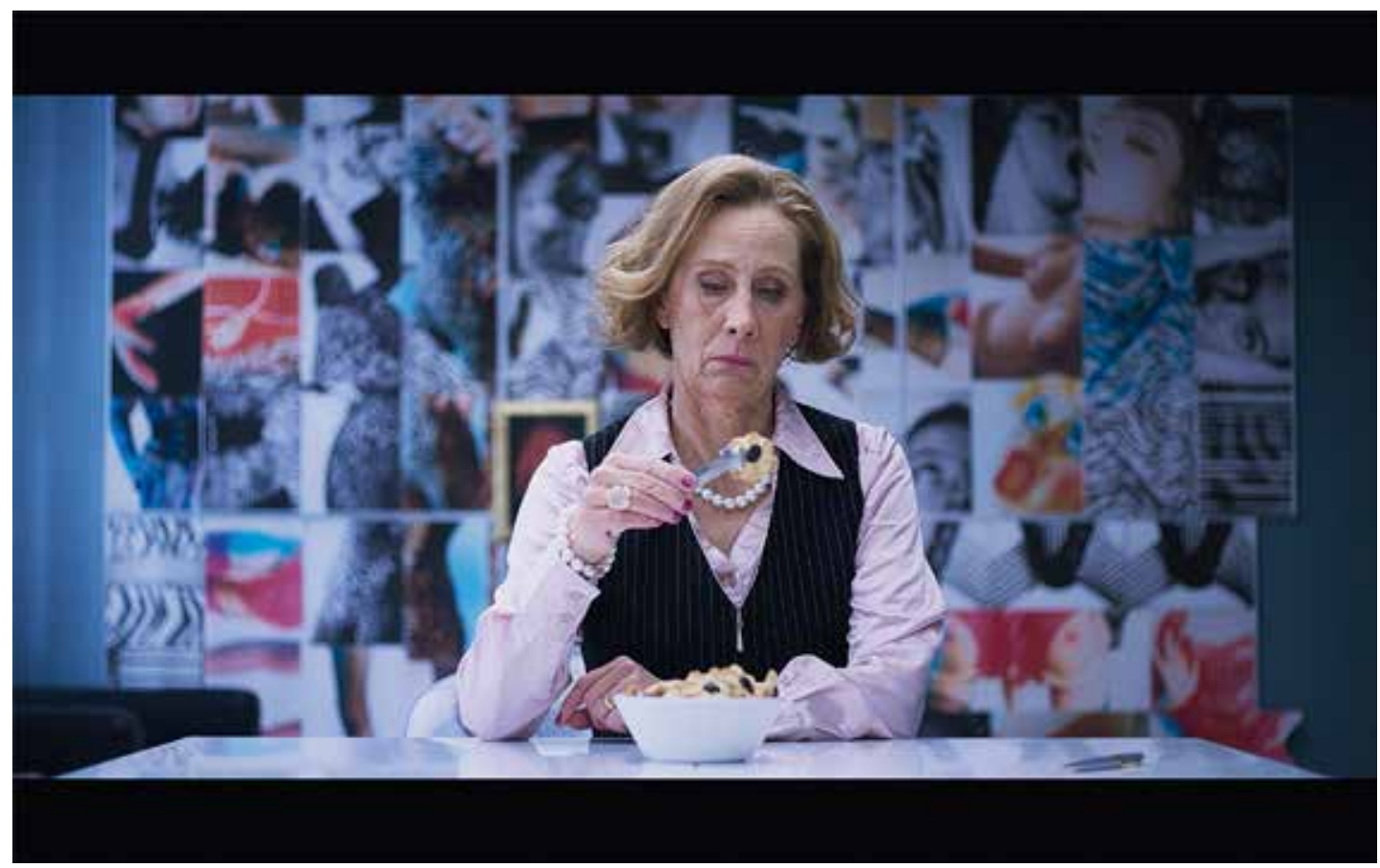

FIGURE 2. Marja Lindroos (Kati Outinen). (Photo: Jekaterina Abramova). 
in Estonia, has been explained and shown mostly through politicians. It is perceived as a kind of a political era and the politicians were its heroes as all the changes that happened in Estonia happened because of the political reforms. Which, I guess, isn't a lie, but that's just one perspective. So, this is the second reason we cut them out and tried to show another perspective.

Paul Aguraiuja: Whatever you create, if you want it to be a piece of art, you can never ask the audience whether they understand or like it. It is as simple as that. If you start asking from the audience if they understand and if they like the material then you go into the mainstream. This is another genre and I don't want to be involved in that.

Why concentrate on the international audience? What the producer says is that the international audience is a means of avoiding an overinterpretation of the series from a national perspecitive.

What we saw in Estonia is that people started comparing it to the real events. This happened automatically. We were dedicating a lot time thinking how can we avoid this interpretation becoming so dominant. How can we eliminate the true background? But it's impossible, as you cannot erase the memories of people; you cannot erase the history. We are not so good that we could re-write history. So, we concentrated on the audiences who don't know the actual background of the story. What I have heard from my partners abroad is that they understand the story perfectly well.

For instance, if the series would be only for the Estonian audiences, then most likely I would choose it to look more like the ' 90 s in Estonia actually were. As we were trying to tell the story to international audiences, it was a deliberate decisions that we would make the world look much more modern, more beautiful, and in that sense unrealistic compared to what the " 90 s were. Because the real '90s in Estonia looked so shockingly ugly that it begins to hinder the storytelling. It is just too much for a contemporary viewer. When we are telling a story to the international audience about a context that they had never heard anything about and about a country that they have never heard anything about, and about a topic - a bank - then this is very difficult, because a very few people actually know how a bank works from the inside. There are so many unknown elements. Should we add a fourth unknown element (besides history, geography and culture) into the storytelling, which is the interior and the costumes? People just can't take it all in. So, if we want to keep those three elements that are new for them, we have to have one element that is comforting, that is relatable. And we decided that this is going to be the visual aspect.

\section{Creating „memory anchors“: tokens of the ' 90 s vs contemporary settings The number of visual elements in „Pank“ seem to be done on purpose. Like the type of clothing that people were wearing, the computers that are shown, etc. Why did you make these choices?}

Tarmo Jüristo: There were many different considerations. It was something that we pretty much initially agreed upon - that we were not trying to shoot a sort of periodbased piece, and try to make it as realistic as we possibly could. We played around initially with some of the aspects. For instance, with clothing and with costumes. Also, we had this casting shoot of Sergo Vares, for instance, where he was made to wear an actual suit from '90s. It just looked awful from the perspective of present day. It was very ill-fitting, loose, and baggy. This is how people walked around in the early '90s. So, what we decided with most of the central characters was that Estonian fashion designer Antonio will make clothes for the series that were inspired by the ' 90 s. He made some subtle, minor adjustments, so that it would look a little better than they originally did.

Then there were other kind of choices. For instance, regarding Hansapank and its interior design, which was very much the same as in many other successful firms in 
Tallinn in the '90s. Curtains were like vertical ribbons and of this ambiguous colour between green and blue. Then you had gray mistra flooring; like carpets, white walls, etc. And there was a lot of use of metal; black furniture and metal. When we had the first test shoots then both the camera operators and the artist for the series said that this is going to look awful, because shooting people against a white background gives a very washed out effect. So, we made the decision to paint all the walls this sort of dark gray, which gives a better contrast and offers better lightning opportunities. So, this change compared to the original setting was a very conscious decision. The interesting thing is that, at one point, when we were already shooting, we had a group of former Hansapank employees come over to the set, and when we walked around everyone said: "This is actually how it was in Hansapank!" And I would point out them that "no, it's really not".

There are a few things that you recognise, such as the computers. We went to the great lengths of getting the original Reuters keyboards on the table. We found a bunch of them somewhere in Latvia and brought them here. You can recognise these "memory anchors" and relate your memories to them and say "okay, all the rest sort of checks out". There are some things that if you concentrate on them and if you ask "tell me, what colour the walls in Hansapank were", they would say "of course they were white". But if there's enough things to convince you that this is familiar then your brain makes this generalisation. It says that yes, basically "this is how it was".

\section{Who made these choices of "okay, we use this computer" versus another one? There are flat screen comput- ers; in reality, I think, in the ' 90 s in Estonia probably there were no flat screen computers?}

Paul Aguraiuja: We agreed that if we would have shown the actual life of the rich people in the ' 90 s in Estonia, they would have looked like clowns. But we wanted them to look serious bankers. The perception of serious bankers of the " 90 s outside of Estonia is completely different than the perception in Estonia. The first plasma TVs came out in '93 and we deliberately put them there, because that was the richest office in the whole country. We wanted to show that they already had future technology. So, every single element in that series was very carefully thought through.

Tarmo Jüristo: I don't think there are any flat screen computers in the early parts of the story. There are flat screen TV's on the wall. But this is something that doesn't really matter, because there were other things where we are not adhering to the real things. I mean, the walls were white - now they're gray. This is, of course, one thing which is easier to replace in your mind. But it is just anachronistic to say that there were no flat screen TVs at the time. But, like I said, we weren't obsessed at all about the historical accuracy. We were not trying to shoot a piece on that particular period. We were trying to just put enough stuff in there to convey the feeling of the " 90 s. That was the main aim.

Eero Epner: I remember our discussion that we would like to avoid nostalgia. So, for example, when people are wearing suits banker's suits - then those are not the suits from the ' 90 s, because they would look stupid in those. Also some things on the screen are not so much about the ' 90 s but they are more like generalised objects. We wanted to show that the period is over and that this is inevitable - and maybe also good because times are different now. I don't like that we are living in more conservative times, but there's no point in having nostalgia toward something which has already gone by.

We wanted to be on the border of strangeness and ugliness. So the characters can be strange, they can act strangely and their motives can be strange, the whole visual context can be a little bit strange, and the music and so on. But, at the same time, not ugly and funny in a bad way. We 
did not want to create a situation where if you look at a banker in this weird suit then you start to laugh and you just don't take the character seriously.

On the other hand, we also didn't want that the people only wore contemporary suits, had contemporary haircuts and objects everywhere. For example, the computers are from the ' 90 s. But if you have too many of these historically coherent artifacts, then the story becomes something else. It's not about drama anymore, but about memories and nostalgia. it begins to look like a visual museum of the ' 90 s and it takes your attention in a direction which we didn't want; that people look at this TV series not as a drama between human beings, and about their wins and losses, but as a TV show about the "90s.

\section{Can you elaborate a little on the symbolism of the whole story?}

Tarmo Jüristo: We had this discussion with Eero after making the series; basically we agreed if we had a chance to do the same story again, we would cut down on symbols. We'd use less of them. It was a conscious choice and I think this is where for both of us the theatre background shines through. In theatre you use symbols a lot more, because they tend to be a very central part of theatre's storytelling. Because you're limited in terms of where you can move and what you can use, so you have to do with less and this means that you reach for symbols.

Eero Epner: We knew beforehand that the story is the most important aspect, but still there were a too many symbols. It came from our inexperience, I guess, because when writing the series I thought, yes, it is just a small symbol. But, eventually, when I saw it on the screen, then it was a big symbol.

I wasn't able to imagine a written symbol on the screen and I didn't understand the difference. Also, one of the directors, Rainer Sarnet, he likes symbols very much. So he also added some extra symbols in the second and third episode. It was not his mistake, I'm not saying that, but it was from our side a little bit bad taste and a lack of experience. We wanted to do a little bit of a strange series, not a realistic one. Because of this some symbols are okay, as we did not want to do a series without symbols.

\section{Remarks by the interviewers: \\ As it become apparent in the interview, the dimension of social contrasts and the related dilem- mas were really important for the authors of the „Pank“ serie. There are at least three more dilemmas that need to be pointed separately: a) the very mascu- line presence of the bankers, there are only very few significant female characters in the story, b) the relations between Estoni- ans and Russians and c) also to what one of the authors - Tarmo Jüristo - pointed: the distinction between documentary, comedy and drama.}

Tarmo Jüristo: The fact that the story doesn't have very many strong female characters is at least partly due to the restrictions of the material - in the early ' 90 s the financial sector in Estonia was a men's world. If you look for historical references for real-life historical persons that could be in this story then they were mostly male. But then you realised that probably more than half female of the audience is female you would need an interesting and engaging female characters.

There's a historical reference that, in the early ' 90 s, close to $40 \%$ of Estonian population was Russian-speaking and, at the same time, there's no Russian-speaking characters in the story. We gave the matter some thought if we should put them in somehow, but since there were actually very few - Hansapank would hire every now and then, but quite rarely, a couple of Russian speaking traders who would cover the Russian market - we only played around with this idea, but in the end just left it 




FIGURE 3. Kalju Tamm (Priit Vöigemast), Pille (Liis Lidmaa), Marju (Tiina Tauraite) (Photo: Jekaterina Abramova). 
aside. We felt that this would have meant stretching the story in too many directions and then it would have been very difficult to handle language-wise. [...] Russian-speaking people at that time of the early capitalist history in Estonia were just largely missing. So we figured that this is a way to document that time and to show that they were being left out.

\section{In Estonia, especially during past couple of years, around 2016-2019 it has become popular to talk about „Swedish colonialism“. Paraphrasing the popular saying that money has no nationality, but nations have money, when making the series, did you think about how this storyline could be interpreted or misinterpreted?}

Tarmo Jüristo: We were playing on that note quite knowingly. I don't care about the colonial aspect that much, but this is clearly there in the narrative. Estonian banker Indrek Neivelt has been talking about that a lot lately and saying that we were exploited and that we are still being exploited by the Swedish financial sector. As such, it was again one of those easy things to take and play with. You know that this is something that will resonate and it gives you a sort of fertile ground on which you can build your story. It gives you a base-level engagement so that people can relate to the story and say "I've heard something like this, or that this is what I felt and this is what I thought about". It is just a tool for creating emotional attachment.

Eero Epner: It was not a coincidence, and we wanted this side to be represented for two reasons. For the people who were the owners of Hansapank, the loss of the bank was very fundamental for them, it was tragic and tragedy always works in TV dramas. So, we wanted to have this story of losing their bank in the TV series. Having them lose the bank to the Swedes was there, not so much because of the colonial point of view, but rather to show that it was inevitable that the Estonians would lose their banks. Not because of the Swedes, but because the Swedes represent something very big. If you were to have Estonians having a bank and then other Estonian businessmen who are trying to buy their bank or rob their bank, then it would represent a kind of a fight between two equals. But when you have a relatively small Estonian bank and then a large Swedish bank, then these two are not equal. And so, it is inevitable that when the Swedes come, they buy up businesses and that there is nothing one can do about it. This feeling that there's nothing you can do to stop the process was an interesting feeling to explore.

\section{Then there's this Finnish director administering in a Swedish bank. Actually, Finns have the history of Swedish colonialism in Finland too...}

Tarmo Jüristo: This is a significance that is purely coincidental, because it wasn't supposed to be Kati Outinen at the beginning. But yeah, this colonial aspect is there, and for instance Marcel Vihmann really didn't like it. And here was also Erkki Raasuke actually asking that "why did you make that story this whole colonial thing? Why did you bring it in?".

\section{Remarks by the interviewers: \\ A story with a retrospective and a (pseudo)historic ambition can be told both ways: as a comedy and/or as a drama. Both authors of the script - Tarmo Jüristo and Eero Epner agreed that the pro- cess of writing the script made it lot more serious than the initial idea of the „Pank“ series was.}

Tarmo Jüristo: There were some things that were just funny, although the final thing that we ended up shooting turned out to be lot darker than the initial version of the script. Less comic relief and a little bit more of tragedy. For instance, we ended up cutting out two characters that were running through all ten episodes and that were 
loosely based on this pair of ' 90 s businessmen, Marek Strandberg and Agu Kivimägi, who were in fact coming over to Hansapank pretty much once every month with another completely crazy idea.

When we handed over the script and this was our first TV script, I think we had something like 240 locations there; we had more than a hundred characters and basically boatloads of things happening. Then the producer and the directors who were a bit more experienced than us said that, you know, this can't be done - we won't have the time, we won't have the money, and it's just simply too much. So, you need to consolidate: not more than 80 locations; a specific limit of characters, etc. We were cutting and saying, "this location has to go out; if there's something important that's happening there, in this location, we need to transfer it to somewhere else". If it's not that important, we just throw the scene out and say, "it doesn't matter, it's going out". And these two characters [Strandberg and Kivimägi] were great characters, but they were not integral to the storyline. Meaning: they were not taking the storyline forward. And this is something that our Danish consultants Steen and Lars were saying: "Always consider, is the scene necessary? Does it take the story forward, does it tell something that the audience absolutely has to know and see? And if not, then just consider scrapping it".

\section{Why did you you go from a comedy- based version to a more drama based mode of storytelling?}

Tarmo Jüristo: It's interesting to remark, the initial idea was to produce a 12-part series. And then, at one point, our Danish consultants Lars and Steen were really trying to convince Estonian Film Institute and The Public Brodcasting (ERR) that since we were a group of people who have never shot anything other than a movie, we should have gone for a mini-series, they suggested to go for a 6-part series. And then, in the end, they kind of found a compromise - they said, "okay, we're gonna have a 10-part series".
We started writing it from the beginning, and we were having a lot of fun. And when we started reminiscing about these times, then all kinds of funny stories would come up. While we were getting to the fifth and sixth episode, then at one point, we realised that if you're just joking around, then the story is not evolving. And so we figured that we'd start a sort of light-hearted and a very easygoing thing, but it would go darker and darker, because in the end, that would be also the premise of the whole series - it was that "when you're winning, you don't see what you're losing". So, you could say that in the first part, we were showing the winning part, and in the second part, we were shedding more light at the losing part: what was the price of all of this, what was the end result, what was the dark side of all that success and fun? I think this was the reason why it became gradually darker thematically.

\section{Did you consider for a while to make it a bit brighter, a bit livelier, a bit funnier?}

Eero Epner: Nope. The central structure was there from the beginning. I guess Tarmo also mentioned that each TV series should have a special name, like a motto. We didn't know that a TV series should have it, but our Danish consultants said that think about this sentence that says what this TV series is about. And we came up with the tagline: "if you win something, you don't see what you are losing”. And that defined the TV series as a story of losing something. It's a story of a loss. And this sentence was very important for us when starting to write it, because we thought that the whole story should show that when you win something, you don't see what you are losing. And also each episode should show winning and losing; and also each character should win something and lose something. So, this contradiction between winning and losing seemed to be interesting. But as the "losing" word was kind of the defining the word, then it became darker and darker. What people [the bankers] lost there - well, 
they lost the ' 90 s, or, the Estonian state lost the '90s. People didn't lose their personal wealth - people are still rich in the end, most of them. But they lost a lot nonetheless. When we interviewed people they didn't all say it in this way, but we saw that the loss of Hansapank was the most important loss of their lives. It wasn't just losing a business adventure or business deal, it was far more than that.

I remember that when we did the first draft of the first episode, we didn't have this sentence yet, and this draft was so much funnier - lots of jokes, and there were even two characters - very funny characters; at least we thought that they were not flat, but comedic. But eventually we cut them out. One of the reasons was because there was no time to show them. But the other reason was that we felt they are not so needed for the series, as it is not defined as a funny story, but as a melancholic story about losing. But, in the beginning, we had some funny moments as well. So it goes.

\section{Did you have a particular audience in mind when writing and producing the series?}

Eero Epner: I guess I didn't. I had the experience of working in a theatre, some say it was kind of an avant-garde theatre, that meant we rarely thought about the audience, in the sense that our aim wasn't to gain the attention of thousands of people, but rather, we concentrated on what we wanted to do, and we hoped that maybe somebody else will like it and will come to see it. And this kind of attitude followed me in writing this TV series. I remember, we discussed with Tarmo that a TV series format is a quite different format when compared to an avant-garde theatre piece, because it will be watched by thousands of people. But I wouldn't say that we kind of discussed the question of the audience. It was important for us that it would be understandable not only in Estonia, but also in foreign countries, but that meant that we wanted to generalize things and not to be too specific.
I would say that some other concerns were a little bit more important.

Paul Aguraiuja: We didn't write down anything - just in order to say that we are making the TV series for this type of person. But as we have been working together for so long, then for us it was quite clear that the series is for an audience who likes to think. It will not become a mainstream product in the sense of viewing pleasure or the viewing experience. So, it's deliberately made as a series that requires that you think and that you analyze it while you watch.

All choices in the story are written so that the person does not need to know Estonian history. The storylines and the plots should be understandable internationally, even if you don't know anything about the background. All the events and what happens to the characters is done as a classic dramaturgy, in the sense that you don't have to know who the characters really are. In Estonia, the real background of the characters is hindering the story. It is not good if you know the real-life prototypes.

This is what we agreed already in the beginning that we will make all the characters in a way that you don't have to know the background. They just have to be interesting characters.

Tarmo Jüristo: It changed over the year and over the course of the work. So, initially we, I think I can speak for both of us (myself and Eero), weren't thinking about the audience much at all, because we weren't thinking of really doing the TV series. The first moment when I started to think that we might actually secure the funding was sometime in the summer of 2016. I started thinking this might become a reality when there were only four projects left. Before that, we were thinking that we are just hanging along and having fun, learning new things in putting this together, but we weren't seriously thinking of actually having to find, for instance, 200 people to shoot the series. Accordingly, we were not very seriously concerned about who would be the viewers 
as we didn't think that far ahead. The point where we were, in a way, forced to start thinking about the audience was when we were selected to be among the four projects that went into development.

\section{How did the wish to sell the series internationally influence your writing of the story?}

Eero Epner: It was important for us that it would be understandable not only in Estonia, but also in foreign countries. That meant that we wanted to generalize things and not to be too specific in some aspects. So that a person who doesn't know the whole context of ' 90 s Estonia will also understand what is going on.

For example, we almost totally cut the political context. One of the reasons for that was the fact that then we would have to also explain it. And it was just too much for a TV series to explain both the overall atmosphere, the political context, and the business context.

Paul Aguraiuja: For me, it's really important to try to sell stories or tell stories that are internationally transportable. And the story of the Estonian ' 90 s is something that the world has not heard about. So that's why for me personally this was the most important and interesting topic to start producing into a series. For me, it's primarily a story about how you start in an absolutely new situation from scratch given the regime change in Estonia in the 1990s. And I believe this is the story that is also interesting for the people also outside of Estonia. Because if you look at other European countries, they started their banks 300 years ago. And for them, it's completely... "oh, wow! You actually started a new country 25 years ago; you had to start banks from scratch!". They have never done it in their recent history. It was their grand-grand-grandfathers, who actually started banks! Nobody, not in modern times, has ever started a bank on this kind of scale and achieved so much. And on the background of the bank, we have the emergence of a brand new society.
So, just to give an example - when l've been going abroad talking about this series in Germany, when I tell them that it's a story about how you start a bank, it's for them, like, "uh-uh, uh-uh..."... and then you start telling them, "but it's a real story - we actually started a new country 25 years ago", then they're all going, "aaah! Ah, you really did!". And they have never heard this story.

We already learned it from the theatre, that when you're telling really local stories but you're telling them in a way that the international audience understands that's the best combination. If you try to do some kind of an international story, it gets lost. It's not interesting for anybody. You have to talk about something really specific, something very local, but tell it in a way that big audiences understand it.

All the choices in the story are written in a way that the viewer does not need to know Estonian history. The storylines and the plots should be understandable internationally, even if you don't know anything about the background.

\section{How did the wish to sell the series internationally influence the shooting/production of the series?}

\section{Tarmo Jüristo: I think the most seri-} ous upshot of that was the visual quality requirements, the sound quality requirements, the camerawork requirements - so, it couldn't be done cheaply; of course it was not an expensive production when compared to "Westworld", "Game of Thrones" and others that are extremely expensive. So, it wasn't the point of doing an expensive thing, but it was a point of producing a quality series that would stand a chance of circulation on the international markets. It was something that you had in mind and in some cases, we were thinking that, "okay, if we do this part, then how would it come across, say, in Sweden or in Finland?". But we weren't changing anything for the international audiences.

Perhaps one of the things that we did do - but there were different reasons for this - was having Kati Outinen that we 
believed would be helpful in the Finnish market [...] l'd be lying if l'd say that this was not in our mind that, you know, that would probably be helpful in terms of selling. But the character was written long before and for story reasons, not for international reasons.

Paul Aguraiuja: The story and the understandability of the story dictated a lot of production decisions... you start with props; you start with locations; you go with the costumes. For example, if the series would be only for the Estonian audiences, then most likely I would choose for it to look more like the Estonian ' 90 s actually were. As we were trying to tell the story to international audiences, it was a clear decisions that we will make the world look much more modern, more beautiful, and in that sense unrealistic to what the Estonian ' 90 s were [...]. If we show the actual life of the rich people in the ' 90 s in Estonia, they look like clowns. But we wanted them to look serious bankers. And the perception of serious bankers of the ' 90 s outside of Estonia is completely different than the perception in Estonia. [...] I'm afraid in that sense, we would have lost the international audiences, if we would have done the series only for Estonians, we would have been showing them [the foreign audience] something like a freak show. We didn't want to do that. We wanted all the audiences outside to take Pank as a real story and watch it for the story.

\section{Are there any differences between the national version and the version that you are selling internationally?}

\footnotetext{
Paul Aguraiuja: The first episode actually is a bit different in the international version - the voiceover is different because the narrator talks directly to international, foreign viewers. The Estonian one doesn't have the explaining voiceover. [...] The archive footage in the first episode is in the Estonian version as well, but there is no voiceover. We don't explain the historical background. If we would have been
}

doing it only for the Estonian audiences, we would have skipped all hints to historical elements. For Estonians, we don't need to explain that much of what happened, but for the international audience there are occasions, where we needed to give them some hints to explain how it is working out.

We first made the international version, and then decided to make the Estonian version without the voiceover. Because it is such an expensive series, we had to make sure that we are able to raise money from the international sales. That was the only option to make it work.

Eero Epner: If I remember correctly, it was after we had shown the first episode to some distributors, that the need to have a longer voiceover for a viewers was raised. So it did not come from us, but from the comments of the foreign viewers. They said that there needs more context explanation and then we just made the voiceover a little bit longer.

Tarmo Jüristo: The change of the voiceover was a last-minute thing, when we had actually the series completed and then realised that this wouldn't work for a foreign audience. We had to do something there.

\section{What did the wish to sell the series internationally influence more: the writing of the story, or the shooting of it?}

Tarmo Jüristo: Shooting. For instance, at some point when the script was taking shape, I remember we were laughing with Eero and saying that this is gonna be a hard to sell in Sweden because of the way the Swedish bankers are depicted in a negative light and them having their own plans with Estonia.
Do you think that producing it also for the international audience compromised its success with the local audience with whom a more tailored story would have been more successful? 
Eero Epner: No - I didn't feel that way, actually, it was a very good tool to think about the foreign audience, because then you generalise and you are not stuck, at least we thought that we will not be stuck, in very concrete things. We also felt that it would just be bad taste to, how to say, make very direct connotations to certain characters and certain happenings in contemporary history. As such, thinking about the foreign audience was actually a good mental tool to cut out what is actually not important. If instead we would have done the TV series for the local audience only we would have brought in some inside jokes and such. But inside jokes are usually not funny, so...

Paul Aguraiuja: Could be, but I would say it made it less acceptable for those people who are used to watching the so-called regular Estonian TV series. They are used to completely different ways of storytelling. But for those people who are, let's say, more accustomed to watching series produced in other countries - for them, the reception was more in line with the international audiences.

\section{Did your approach to considering an international audience change at any point during the writing or production of the series?}

Eero Epner: No, already when the competition was announced, then one of the rules of this competition was that it must also be understandable for a foreign audience. So, we agreed in the beginning that yes, we'll try to do this kind of a TV series, which a person in Sweden can also understand. But then we dropped this discussion. We didn't discuss it at all anymore. It was kind of an agreement, and later on, other questions were more important than the questions connected with the audience.

Tarmo Jüristo: The international dimension was there all the time, from the beginning. As I said before, I think we didn't spend too much time thinking about the audience, but yes, the basic point that it would have to have a potential to be sold for foreign markets markets was there from the beginning.

Paul Aguraiuja: We agreed already many years ago, when we had the first ideas of this series, that we want to prove that it's possible to distribute an Estonian series outside Estonia. That this country has the talent, it has all capabilities to produce an internationally acceptable series.

\section{Did you get international support/ advise when writing and producing the series?}

\author{
Note: The Estonian Film \\ Foundation provided the produc- \\ tion with some help from Frans \\ Baunsgaard and Steen Bille
}

Eero Epner: We simply didn't have any money to have a script doctor from outside Estonia. There were two Danish persons. But they were more like schooling us. And later, we also sent them the script but they didn't even read it, so I don't remember any foreign persons who would have read the script.

Paul Aguraiuja: During the writing and development process, we had two consultants from Denmark. One producer and one really experienced writer. They helped us a lot with structure and regarding reading. I think they read only the first episode, not the later ones. They were hired by the Estonian Film Institute to consult all the four finalists of the Estonia 100 competition.

\section{And what about a support for the international sales?}

Paul Aguraiuja: In the beginning, during the first month, the Estonian Film Institute hired one consultant, who actually got me the first meetings with some sales agents and distributors. She later arranged some other meetings for me.

We told them, the Estonian Film Institute, already from the beginning, that 
we want this to be a really international series. We are not satisfied if the series stays only in Estonia. And so they were continuously working with us to get there and they took a huge risk with us, because they knew that our budget is double the amount that they are giving us, and they also knew that we did not currently have full coverage for our part of the budget. They believed in us and the fact that we would be able to raise the rest of the money during production.

\section{Coming from the small Estonian market, did you face any challenges in writing, producing and selling the series particular to a lack experience and expertise?}

Eero Epner: We, Tarmo and I, we didn't have any experience in writing a TV series or in writing movies. And also, we didn't think that there's somebody in Estonia who would have this kind of experience with writing this kind of TV series that we wanted to create - because other TV series in Estonia are more similar to soap operas. I'm not trying to be arrogant here - it's just the way it is in Estonia. We thought that there is no such expertise in the Estonian movie industry that could say that this character doesn't work, or here you move on too fast and here too slow. So, we were missing proper expertise.

Paul Aguraiuja: It has been more interesting to do international collaborations, because if you work only with a small audience in a really small country, then it's really easy to get the understanding that what you are doing is fine and it's really easy to get comfortable with that understanding. Regarding the international sales, we have been completely alone, because in Estonia, there's absolutely no one who has done it before. There was basically nobody to ask questions from. Absolutely nobody. In the beginning, during the first month, the Estonian Film Institute hired one consultant, who actually got me the first meetings with some sales agents and distributors.
But from then on, when I already had my foot in the business, I was on my own.

\section{How did international buyers react to you trying to sell them an Estonian series?}

Paul Aguraiuja: I felt like I was one of those people from Nigeria who send you those lovely e-mails, that "I have an amazing offer for you!". I was one of those moments. I have taken cold contacts with tens and tens of people from different TV channels, different distributors, different festivals and then I luckily received a few answers.

We decided to invest half of our development budget into producing a trailer.

The trailer cost us more than one episode of TV series costs in Estonia, and it was... now, looking back, it was the wisest decision we made. Because when you come from a country from which nobody has ever seen any series from, the wall that you have to break through is really thick. You have to prove that you are serious, then you have to show that you have a really good story that you want to tell, and then you have to prove that you can actually make it work, that you can actually produce it. You have to show the actual quality of how the series will look. So, we invested a lot in making a good trailer. The script of the series was not even finished yet. We just wrote the script of the trailer and then produced it.

The Estonian market is microscopic. So, if you go to... let's say, not to the countries that are next to us, but if you go further, then they make one episode for the money that we made the whole series with.

TV-wise, money means so much. The production value that you can give for the budget that the Estonian TV channels are able to provide is so low that nobody will take you seriously. Even with this series, talking with potential distributors, they all asked: "how can you possibly produce it with so little money, for such a small amount?".

Marketing-wise, it's extremely complicated - to include international marketing money. Because then you have to show 
international outputs in advance. Which means you have to have some big European TV channels co-producing the series with you.

\section{How are you selling the series now?}

Paul Aguraiuja: I have an agent in London who does the actual selling work. We had the series already finished, and then I found him through the Series Mania Festival. And basically, because all the agents go there, to look for new content..... and then, this one guy really liked Pank and we found a good agreement, and now his selling it for us. $\mathrm{He}$ already has the contacts with TV channels. He doesn't make those cold calls. He can actually write to people he knows. Talk to people who he knows. And, secondly, it gives much more seriousness to the project. If I'm just some guy from Estonia, it's so much harder, because Estonia is not known as a country for top content.

\section{Do you think this will change any time?}

Paul Aguraiuja: If there will be more content like Pank then yes, there's potential. But if everything continues the same way, and all the budgets for TV series come from the local channels, then I don't see much potential.

It's also a question of ambition. There are very few TV producers in Estonia who actually have the ambition to take on the role of selling your TV series internationally. Even if you don't have any money at all, there are so good opportunities to find a thousand euros, buy yourself a plane ticket and get a hotel room in France and go out to pitch your ideas. You might get lucky. If your idea is really good, it will definitely be picked up by major producers, international co-producers.

\section{But why is it missing, the ambition?}

Paul Aguraiuja: I really don't know. I think there will be some kind of a generational shift quite soon. Some months ago, there was a conference here in Estonia about the future of Estonian TV series industry. And then all the old-school gentlemen who have been producing TV series here for 20 years, they were expressing ideas that they want to continue the same way and all they are talking about is why the local channels are paying such small amounts of money. But all the younger ones who are coming up, they understand that if they want to do something bigger, there's no point in yelling at the local TV channels, because they will get poorer by time they start paying out more. You have to go abroad to attract the money. So, I'm really hoping that there will be some kind of a change in ambition with the new generation of producers coming up.

But then there is also the risk that they will move and stay abroad...

Paul Aguraiuja: Yes, of course.
You have not sold the series to many international markets, yet. Only to Finland, US, Latvia, Lithuania and Hungary. And in some of these countries, the series is still yet to air. Do you know if the audience liked the series in places where it has already been aired?

Paul Aguraiuja: I don't have any feedback yet from the international TV channels. It has been on air only in Latvia. The next country will be broadcasting it in the end of summer, so I don't have the actual audience feedback. The Finnish main channel YLE will start on July $24^{\text {th }}$. And in the US, they also start in the end of the summer. So, I'm really looking forward to actually hear what the audience thinks and critics think there. But I don't have any feedback from that.

\section{What have you heard from interna- tional buyers why they bought or not bought the series?}

Paul Aguraiuja: All the feedback that l've gotten from the international buyers - they are telling me that it's just the story, and 
the background that it's based on true events - this is what makes it interesting for them. And all the events - what happens to the characters - this is, I would say, classic dramaturgy, in the sense that you don't have to know who they really are. In Estonia, the real background of the persons... , it's hindering - it's not good even, if you know. You can enjoy the series much more if you don't know that this is Jüri Mõis and this is Tiina Mõis. Because in Estonia, what we saw, is that people start comparing it to the real events. It happened automatically.

In Sweden, they told me really precisely that this is not mainstream enough and that they can't show it on the main national channel, because it most likely will not generate enough audience. And they said it's also a matter of storytelling - that you have to think a lot, because it's not an easily consumable series. Even though it has so many connections with Sweden, but they said that as SVT1, their main national channel, "it's a mainstream channel, we are only looking for the potential audience number, and ... the computer says no".

They are not the only ones who have been saying that it's very hard for them to take the risk to show an Estonian series in Estonian language. In Sweden this is not the case, but in some countries people have still not heard about Estonia, and even if they knew that there is such a country, they have never heard the language. So, for us the easier markets are those who do a complete new audio, a full dubbing. Those are much easier, because they don't have to deal with their audience's fear of new languages.

For Latvia - and now also Lithuania decided to buy it - they want to show the story of their neighbor, because we are so tightly connected to each other.

\section{What is your strategy, to what countries you are selling it next?}

Paul Aguraiuja: At the moment, we are currently working with Eastern Europe, because topic-wise, we can see there are many more connections. After that, we move to Western Europe, including the Scandinavian countries.

As the Hungarians are doing full dubbing and, for them, we have to produce this kind of special version of the series that is designed to be dubbed. When we have produced it, it will open up new markets in those sections of the world where they do only dubbing. So, the next one we'll start going to are all the Spanish-speaking countries, because this is a large group of countries.

\section{Is there a difference as to how the series is promoted internationally vs. in Estonia?}

Paul Aguraiuja: If we had also said in Estonia that this is based on real events, we would have been doomed. Everyone would have been looking at Pank as a documentary. Now, of course the journalists, the media, and the public reception they all automatically started comparing the events in the series and the events in the real life. But in all our comments, we tried to mitigate this aspect. But on the other side, when we go outside of Estonia, then we really push the fact that this is a true story.

\section{How do you see changes in the international market, especially for players from small markets, such as Estonia?}

Paul Aguraiuja: In the current world of producing TV, where you come from doesn't matter so much anymore. It's only about the idea. You have to have an amazing idea and you have to be able to prove that you can actually produce it.

\section{But as you described it earlier, it did matter for you that you are selling out of Estonia...?}

Paul Aguraiuja: Of course. Yes.

So, it did matter. 
Paul Aguraiuja: I would say it has been a five-year process. There has been a slight shift. The TV channels have become more open to territories they have not bought from or co-produced with before. The audiences and therefore also the TV channels, they are in constant search of something new.

The MHz Network in the US has been the one who has started the trend of showing Nordic noir in the US. They were the ones who took "Borgen" into the US and made it a huge hit. And they told me that they are predicting that the Scandi-noir will be boring really quickly and that now they have entered the time when they want to change the mind of, let's say, the hippest people in New York. When they used to say to each other that "I'm watching this Scandi-noir series in the evening, this is so cool". So now they want them to tell to their friends that they're watching this strange Estonian drama. So it's the constant search for the new.

Tarmo Jüristo: Now that l've been going to all kinds of different TV series conferences, workshops, meet-ups in Scandinavia, then, you know, Netflix people come to the stage and said "don't try to produce an international story - produce a local story and we'll take care of the translation and bring it to the foreign audiences". So, the audiences don't want an international story, they want something with a local flavour and this is something that catches their interest. 